\title{
Plasma Insulin Response in Pregnant and Non-Pregnant Rats: Effects of Different Dietary Carbohydrates
}

\author{
A. R. Bourne ${ }^{1}$, B. C. Whaler, and J. Yudkin \\ Queen Elizabeth College, University of London, London, England
}

Summary. The effects of prolonged feeding of diets containing various carbohydrates on the plasma insulin response to glucose (given intravenously) have been investigated in 20-day pregnant rats and compared with the effects in non-pregnant rats. In pregnant animals the insulin response was similar for all diets; the insulin concentration was approximately $120 \mu \mathrm{U} / \mathrm{ml}$ for at least $10 \mathrm{~min}$ after injecting glucose. In non-pregnant rats, except those fed glucose, the insulin response was lower than in pregnant rats. The mean insulin concentrations were 80,70 and $50 \mu \mathrm{U} /$ $\mathrm{ml}$ at $2.5,5$ and $10 \mathrm{~min}$ after intravenous glucose. The effect of glucose feeding was to increase the response in non-pregnant animals so that it approached the values found in pregnant animals. The maximum concentrations of plasma insulin for glucose-fed pregnant and non-pregnant rats were $141 \pm$ 23 and $134 \pm 15$ (SEM) $\mu \mathrm{U} / \mathrm{ml}$ respectively. It was concluded that the increased availability of glucose in the diet during pregnancy plays a role in regulating the insulin secretory response.

Key words: Dietary carbohydrates, pregnancy, rats, insulin response to glucose.

Studies in man and other animals have shown that the hormones of pregnancy can modify insulin secretion [17]. However it has recently been shown that insulin secretion during pregnancy is greatly influenced by the diet of the pregnant animal, and especially by its carbohydrate content [10]. This finding agrees with other work showing that both the amount

\footnotetext{
1 Present address: Biological Health Sciences, Deakin University, P. O. Box 125, Belmont, Victoria 3216, Australia
}

and the nature of the dietary carbohydrate affect insulin secretion [10]. The substitution of starch by sucrose in a high carbohydrate diet leads to an increased plasma insulin response and a decreased glucose tolerance $[8,14]$.

In a previous study we examined the effects of different dietary carbohydrates on metabolism in the rat during pregnancy [3]. The aim of the present investigation was to compare, in vivo, the effects of both different dietary carbohydrates and pregnancy on the plasma insulin response to intravenous glucose. A preliminary report of this work has been published [4].

\section{Materials and Methods}

The female rats used in these experiments were of the SpragueDawley ASH/CSE (Scientific Products Farm Division, Charles River, U. K. Ltd.). In each experiment the rats were weaned at 22 days and randomised into two groups. In experiment 1 , rats were fed for 7 weeks on diets with either sucrose or starch. In experiment 2, they were fed for 19 weeks on diets with either fructose or glucose. The diets consisted of carbohydrate $680 \mathrm{~g} / \mathrm{kg}$; casein 230 $\mathrm{g} / \mathrm{kg}$; corn oil $16 \mathrm{~g} / \mathrm{kg}$, with appropriate mineral salts and vitamins [6]. Control animals were given a stock diet of Oxoid cubes (Lillico and Son Ltd., Betchworth, U. K.), containing 49\% starch.

Food and water were given ad libitum. We have previously shown that there is no difference in food intake in rats fed these diets $[6,7]$. Rats on all diets gained weight at the same rate. The average weight gain during the first six weeks on the diets was $140 \mathrm{~g}$. Mating procedures and animal housing conditions have been described previously [3]. The first day of pregnancy was taken as the day when mating occurred.

Plasma insulin response to glucose was measured in rats fasted overnight. Measurements were performed on rats anaesthetized with sodium pentobarbitone $(40 \mathrm{mg} / \mathrm{kg}$ body weight) administered intraperitoneally. The response of pregnant rats was measured at day 20 of pregnancy.

Glucose $(0.625 \mathrm{~g} / \mathrm{kg}$ body weight $)$ was administered into the jugular vein over a period of $20 \mathrm{sec}$. Blood samples $(0.6 \mathrm{ml})$ were obtained, via a cannula in the carotid artery, 10 and $2 \mathrm{~min}$ before, and $2.5,5,10,30$ and $60 \mathrm{~min}$ after injection of glucose. The 


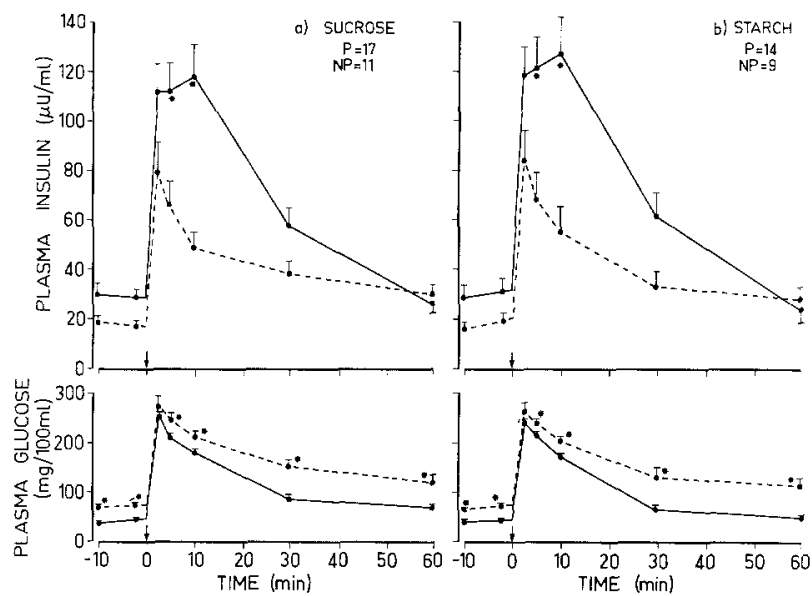

Fig. 1. Mean concentrations of plasma insulin and plasma glucose before and after an intravenous injection of glucose (indicated by arrow) in rats fed (a) sucrose and (b) starch diets. Number of animals in each group is indicated on the graph; $\mathrm{P}$ indicates 20 -day pregnant group (-); NP indicates nonpregnant group (----); vertical bars indicate \pm SEM; significant differences between pregnant and non-pregnant values are indicated by asterisks, ${ }^{*} \mathrm{p}<0.05$

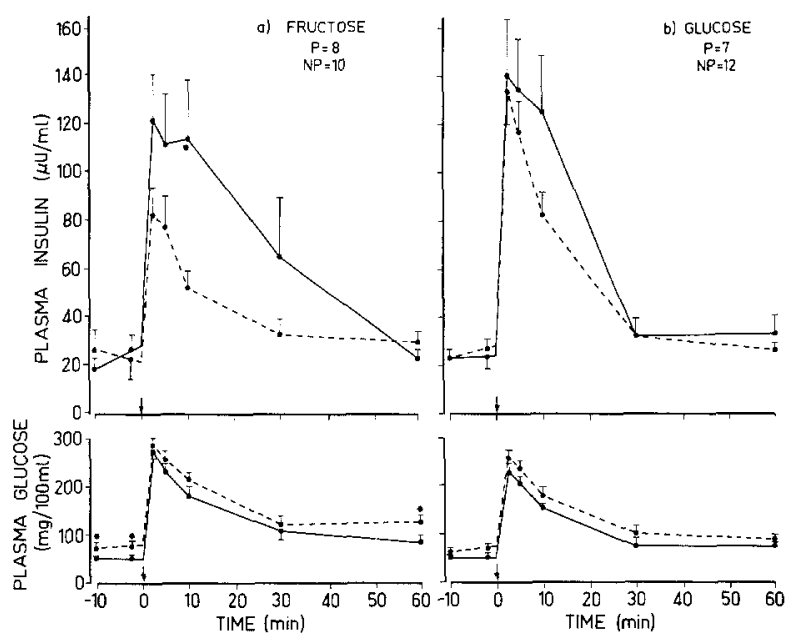

Fig. 2. Mean concentrations of plasma insulin and plasma glucose before and after an intravenous injection of glucose (indicated by arrow) in rats fed (a) fructose and (b) glucose diets. $P$ indicates 20-day pregnant group (-) NP indicates non-pregnant group (----); vertical bars indicate $\pm \mathrm{SEM} ;{ }^{*} \mathrm{p}<0.05$

animals were left for a period of $30 \mathrm{~min}$ after completing the surgical procedures before beginning the experiment. This was to allow for any possible effects of stress due to surgery. In a preliminary study it was established that neither anaesthesia with sodium pentobarbitone nor intravenous injection of saline were associated with any significant changes in fasting levels of plasma glucose or plasma insulin.

Plasma glucose was assayed by a modification of a glucose oxidase method. Plasma insulin was measured by a radioimmunoassay technique [11]. Assay materials were obtained from the Radiochemical Centre, Amersham (U.K.). Insulin of human origin was used as standard, and values of plasma insulin are expressed in equivalents of human insulin. Between-assay precision was assessed by using samples from a plasma pool; mean value (10 assays) $50.0 \pm 2.2$ (SD) $\mu \mathrm{U} / \mathrm{ml}$. The assay was sensitive to less than $5 \mu \mathrm{U} / \mathrm{ml}$. Statistical analysis was carried out by the Student $\mathrm{t}$ test.

\section{Results}

In experiment 1 the mean body weights before mating were: sucrose $202 \pm 4 \mathrm{~g}$; starch $199 \pm 4 \mathrm{~g}$ ( \pm SEM). In experiment 2 the weights were: fructose $271 \pm 4 \mathrm{~g}$; glucose $278 \pm 5 \mathrm{~g}$. There was no difference in the gain in body weight during pregnancy between dietary groups within experiments. The average weight gained during pregnancy was $103 \mathrm{~g}$ (experiment 1) and $72 \mathrm{~g}$ (experiment 2).

In 20-day pregnant rats the insulin response to intravenous glucose was similar for all diets. In nonpregnant rats, except those fed glucose, the response was considerably lower than in pregnant rats (Fig. 1 and 2). The effect of prolonged glucose feeding was to increase the response so that it approached the values found in the 20-day pregnant rats (Fig. 2b). The results for animals fed the stock diet were similar to those fed sucrose, starch, and fructose diets.

\section{Experiment 1: Sucrose Versus Starch Diet}

The results were similar for both sucrose-fed and starch-fed rats. The insulin response was greater during pregnancy (Fig. 1). The fasting insulin values were about $20 \mu \mathrm{U} / \mathrm{ml}$ in the non-pregnant rats and about $30 \mu \mathrm{U} / \mathrm{ml}$ in the 20 -day pregnant rats, but these differences were not significant $(p>0.05)$. In pregnant animals the mean concentration of plasma insulin remained elevated at about $120 \mu \mathrm{U} / \mathrm{ml}$ for at least $10 \mathrm{~min}$ after injection of glucose. In the nonpregnant rats the concentrations were approximately 80,70 and $50 \mu \mathrm{U} / \mathrm{ml}$ at $2.5,5,10 \mathrm{~min}$ after glucose administration. The mean values for plasma insulin were significantly higher $(\mathrm{p}<0.05)$ in pregnant groups at 5 and $10 \mathrm{~min}$.

The concentrations of plasma glucose were similar in both dietary groups. In pregnant animals the concentrations were lower than in non-pregnant animals both before and after glucose injection (Fig. 1).

\section{Experiment 2: Fructose Versus Glucose Diet}

The results for the fructose-fed rats were similar to those for the starch-fed and sucrose-fed rats (Fig. 2). However, the results in the glucose-fed rats differed in some respects from those in rats on the other diets (Fig. 2). Thus, there was no difference in glucose-fed rats between the concentrations of plasma insulin in 
pregnant and non-pregnant rats; the maximum concentrations were $141 \pm 23 \mu \mathrm{U} / \mathrm{ml}$ and $134 \pm 15 \mu \mathrm{U} /$ $\mathrm{ml}$ (mean $\pm \mathrm{SEM})$. Again, pregnancy made no difference to the fasting concentration of plasma glucose. On the other hand, the maximal concentration of plasma insulin in pregnant rats was no different in glucose-fed animals from that in animals fed the other carbohydrates.

In pregnant animals on all diets there was a tendency for the insulin response in the pregnant rats to remain at peak concentrations for a longer period after injecting glucose. In the non-pregnant rats there was a fall in the mean concentration of plasma insulin between 2.5 and $10 \mathrm{~min}$ after injection of glucose (glucose- and fructose-fed rats, $\mathrm{p}<0.05$; starch- and sucrose-fed rats, $p<0.1$ ). In pregnant rats plasma insulin remained at or near the maximal concentrations for at least $10 \mathrm{~min}$.

\section{Discussion}

During pregnancy there is an increased plasma insulin response to glucose. In pregnant women this response increases gradually from early gestation onwards [19]. In the rat there is no evidence of any increase in response at day 12 of pregnancy although an increase is evident at day 20 [5]. In the present study 20 -day pregnant rats on all diets, excepts glucose, had a greater insulin response to intravenous glucose than did non-pregnant rats. Costrini and Kalkhoff [9] showed similar differences between pregnant and non-pregnant rats, although their earliest measurement of plasma insulin was 10 min after glucose injection. In the present experiments the measurement of plasma insulin 2.5 and 5 min after glucose injection revealed a difference in the pattern of response between the pregnant and non-pregnant animals. The peak of the insulin response was spread over a longer period in the pregnant animals (Figs. 1 and 2). This difference in response suggests that during pregnancy the biphasic mechanism for insulin release is modified so that the initial phase of the response in enhanced. It has been reported that pentobarbitone anaesthesia causes some exaggeration of the insulin response to intravenous glucose, although the total insulin area, up to $30 \mathrm{~min}$, is not affected [2]. In the present study we have assumed that any such effect is constant between diets.

Recently Green and Taylor [10] have questioned the assumption that changes in insulin secretion during pregnancy occur mainly due to the action of pregnancy hormones. They suggest that the carbohydrate content of the diet exercises an important role in regulating the insulin secretory response during pregnancy.
It is well established that diets rich in carbohydrate lead to an increase in insulin response to glucose [12]. However the extent of the increase depends upon the nature of the carbohydrate. Feeding rats on a sucrose diet produces a greater increase in glucose-induced insulin secretion than does feeding starch $[8,14]$. In the present study we found no difference between feeding starch or sucrose in either pregnant or non-pregnant rats. This discrepancy between our results and those of Laube et al. [14] appears to be resolved by a later study in which it was shown that only the later phase of insulin release is elevated by sucrose feeding, and that the early insulin response is not different in sucrose-fed and starchfed rats [15]. The considerable elevation of the late 'plateau-like' response of insulin to an increased glucose concentration, which results from sucrose feeding [15], may be involved in producing at least some of the various metabolic changes that are found in animals fed on this diet $[1,16]$. The fructose moiety in sucrose is thought to be responsible for these changes [3]. Thus in the present study we have also compared fructose and glucose diets.

The insulin response to glucose in 20-day pregnant rats was similar for all diets. However the insulin response in glucose-fed nonpregnant rats was greater than in non-pregnant rats fed the other carbohydrates. This might be explained if there is a more rapid absorption of glucose following a glucose meal compared with other carbohydrate meals as reported by Naismith and Rana [18]. It appears that the glucose-fed rats adapt by an increase in the sensitivity of the pancreatic $\beta$-cell to a rise in plasma glucose [12]. In the present study our main purpose was to compare the effects of different dietary carbohydrates. For this reason we have not included a low carbohydrate diet. However we have measured the insulin response in rats fed a stock diet containing $49 \%$ starch. The results were substantially the same as those for the sucrose, starch, and fructose diets. In the experiments of Costrini and Kalkhoff [9] the rats were fed a stock diet which contained $58 \%$ carbohydrate.

If the effects of diet and pregnancy on insulin response are independent then one might expect that the response in glucose-fed rats would show a further increase during pregnancy. Although there was a slight increase it was not significant. This suggests that these effects are, at least in part, related. Furthermore the increased insulin response produced by glucose feeding appears to be able to deal with the metabolic demands of pregnancy without any further substantial increase in response, since there is no obvious impairment of glucose tolerance in pregnant glucose-fed rats (Fig. 2). It has been reported that in 
the rat, pregnancy increases active transport of glucose across the intestine [13]. This is thought to be the result of the increased food intake during pregnancy. It is possible therefore that the increase in insulin response to glucose which occurs during both pregnancy and glucose feeding is largely due to the more rapid entry of glucose into the circulation following a meal. We suggest that this increased availability of glucose occurs in pregnant rats regardless of the type of carbohydrate in the diet (since it is due to the effect of increased food intake), and occurs in non-pregant rats only when fed glucose diets. Thus the nutritional changes during pregnancy may play an important role in increasing insulin response to glucose, as Green and Taylor [10] have suggested. Although this is probably not the only influence on the pancreatic $\beta$-cell during pregnancy as shown by investigations into the effects of pregnancy hormones [17].

\section{References}

1. Akinyanju, P. A., Yudkin, J.: The effect of dietary carbohydrate on serum lipids of rats. Proc. Nutr. Soc. 26, 31 (1967)

2. Aynsley-Green, A., Biebuyck, J. F., Alberti, K. G. M. M.: Anaesthesia and insulin secretion: the effect of diethyl ether, halothane, pentobarbitone sodium and ketamine hydrochloride on intravenous glucose tolerance and insulin secretion in the rat. Diabetologia 9, 274-281 (1973)

3. Bourne, A. R., Richardson, D. P., Bruckdorfer, K. R., Yudkin, J.: Some effects of different dietary carbohydrates on pregnancy and lactation in rats. Nutr. Metab. 19, 73-90 (1975)

4. Bourne, A. R., Whaler, B. C., Yudkin, J. Effect of different dietary carbohydrates on insulin response in pregnant and non-pregnant rats. J. Endocrinol. 71, 89-90 (1976)

5. Bourne, A. R., Wilson, J.: The effects of pregnancy and pseudopregnancy on plasma insulin response to glucose in rats. Proc. Aust. Physiol. Pharmacol. Soc. 8, 6 (1977)

6. Bruckdorfer, K. R., Khan, I. H., Yudkin, J.: The effect of chromium on the hyperlipaemic action of sucrose. Nutr. Metab. 13, 36-43 (1971)

7. Bruckdorfer, K. R., Kang, S. S., Khan, I. H., Bourne, A. R., Yudkin, J.: Diurnal changes in the concentrations of plasma lipids, sugars, insulin and corticosterone in rats fed diets con- taining various carbohydrates. Horm. Metab. Res. 6, 99-106 (1974)

8. Cohen, A. M., Teitelbaum, A.: Effects of dietary sucrose and starch on oral glucose tolerance and insulin-like activity. Am. J. Physiol. 206, 105-108 (1964)

9. Costrini, N. V., Kalkhoff, R. K.: Relative effects of pregnancy, estradiol and progesterone on plasma insulin and pancreatic insulin secretion. J. Clin. Invest. 50, 992-999 (1971)

10. Green, I. C., Taylor, K. W.: Insulin secretory response of the isolated islets Langerhans in pregnant rats: effects of dietary restriction. J. Endocrinol. 62, 137-143 (1974)

11. Hales, C. N., Randle, P. J.: Immunoassay of insulin with insulin-antibody precipitate. Biochem. J. 88, 137-146 (1963)

12. Howell, S. L., Green, I. C., Montague, W.: A possible role of adenylate cyclase in the long-term dietary regulation of insulin secretion from rat islets of Langerhans. Biochem. J. 136, 343-349 (1973)

13. Larralde, J., Fernandez-Otero, P., Gonzalez, M.: Increased active transport of glucose through the intestine during pregnancy. Nature 209, 1356-1357 (1966)

14. Laube, H., Fussganger, R., Goberna, R., Pfeiffer, E. F.: Zur Bedeutung einer isocalorischen stärke- oder rohrzuckerreichen Nahrung auf die Insulinsekretion und Glucoseassimilation. Klin. Wochenschr. 50, 239-242 (1972)

15. Laube, H., Schatz, H., Nierle, C., Fussganger, R., Pfeiffer, E. F.: Insulin secretion and biosynthesis in sucrose fed rats. Diabetologia 12, 441-446 (1976)

16. MacDonald, I., Braithwaite, D. M.: The influence of dietary carbohydrates on the lipid patterns in serum and adipose tissue. Clin. Sci. 27, 23-30 (1964)

17. Malaisse, W. J.: Hormonal and environmental modification of islet activity. In: R. O. Greep, E. B. Astwood (eds.): Handbook of Physiology, Section 7, Vol. 1, pp. 237-260. Washington: American Physiological Society 1972

18. Naismith, D. J., Rana, I. A.: Sucrose and hyperlipidaemia. II The relationship between the rates of digestion and absorption of different carbohydrates and their effects of enzymes of tissue lipogenesis. Nutr. Metab. 16, 285-294 (1974)

19. Spellacy, W. N., Goetz, F. C., Greenberg, B. Z., Ells, J.: Plasma insulin in normal "early" pregnancy. Obstet. Gynecol. 25, 862-865 (1965)

Received: December 5, 1977,

and in revised form: February 2, 1978

Dr. A. R. Bourne

Department of Physiology

Monash University

Clayton, Victoria 3168

Australia 